\title{
INTERNATIONAL CO-OPERATION IN AFRICAN BOTANY
}

COME seventy members and guests of the Association $\checkmark$ pour l'Etude Taxonomique de la Flore d'Afrique Tropicale held their second plenary meeting at Oxford during September 29-October 3. The full text of the scientific papers read will be published in Florence in the journal Webbia, under the editorship of Prof. R. E. G. Pichi-Sermolli. The following is a brief account of some of the more important results.

After the introductory address of welcome by the president, Mr. A. W. Exell (British Museum, Natural History), Dr. W. Mullenders (Brussels) read a paper on "The Phytogeographical Elements and Groups of the Region of Kaniama (High Lomami-Belgian Congo)". He stated that it is possible to analyse floras according to the phytogeographical groups represented : first, the basic element characteristic of the region dealt with ; secondly, connecting groups characteristic of two or several regions; thirdly, pluri-regional groups (palæotropical, pantropical and cosmopolitan); and fourthly, endemics. Dr. Mullenders on this basis made an analysis of the flora of the region of Kaniama (841 species), using the phytogeographical territories established by Lebrun. $\mathrm{He}_{e}$ found that $31 \cdot 3$ per cent ( 263 species) belonged to the Guinean element and $31 \cdot 4$ per cent (264 species) to the Sudano-Zambesian element. Plants of the connecting groups comprise $15 \cdot 3$ per cent (129 species); endemics 1.7 per cent (14 species); and species widely spread $20 \cdot 3$ per cent (171 species). The connecting groups showed a decided bias in favour of the Guinean region. The Guinean element was highest in the wetter grass communities and lowest in the dry grass communities, and conversely with the Sudano-Zambesian element. Degradation by fire led to reduction of the Guinean element, while absence of human interference favoured the development of equatorial forest, with, of course, a high proportion of Guinean species. The climax is thus mainly represented by the Guinean element, but the impact of man tends to favour Sudano-Zambesian species. The Kaniama district is thus to be placed in the Guinean region, though close to the boundary of the Sudano-Zambesian region.

Dr. Hugh Scott described and vividly illustrated an adventurous journey to northern Ethiopia, particularly the mountainous High Simien, during November and December 1952, mainly to study the insect fauna of high elevations. His route was from Asmara across the Tacazzé River to Debárec and thence to the High Simien, Gondar and Lake Tana. $\mathrm{He}$ visited Mt. Buahit (14,796 ft.) and Ras Degien $(15,154 \mathrm{ft}$.$) , the highest peak in Ethiopia. On the$ latter, L. rhynchopetalum and the spiny Helichrysum citrispinum were characteristic of high altitudes. Here true snow occasionally falls; but Dr. Scott only encountered frozen hail. Among other plants illustrated were tree-heath, bamboo, a giant Echinops and Kniphofia. The only giant lobelia was $L$. rhynchopetalum, the hollow stems of which are used as trumpets; $L$. giberroa, so abundant in parts of central and southern Ethiopia, and also in Eritrea, was not seen. The top of the plateau of the High Simien has been mostly cleared, but juniper trees around churches give evidence of its original vegetation. No Podocarpus was seen.

Dr. J. Léonard (Brussels) directed attention to the difficulties encountered in interpreting large hetero- geneous genera-whether to maintain them and at the same time perpetuate bad taxonomy, or to put them in order by making them homogeneous. In order to divide heterogeneous genera, it is necessary to take into account the hierarchy of characters, to study all the species, and to assess the correlation of characters, which may be primary characters derived from the morphology of the flower, or secondary characters which are vegetative and often minor but nevertheless most useful. Good genera should have correlation between primary and secondary characters. Genera with primary characters only are doubtfully valid, and with secondary ones only even more suspect. Where secondary characters are in opposition within a genus, it may imply the existence of overlooked primary ones. He emphasized the need of uniformity in the treatment of genera.

Species of the savannah and miombo are often extremely variable and thus to some extent subjective, while in forest species there is, on the other hand, a tendency to fixity of characters, thus making the species objective. Bad taxonomy and a mixture of species is often implied by a very variable forest species, or by geographical or ecological discontinuity. Dr. Léonard gave examples in the genera Guibourtia and Afzelia. He finally emphasized the need for systematists to study all available material of a group.

Prof. P. Duvigneaud (Université Libre, Brussels) then discussed "La Géographie des Caractères et l'Étude de la Flore Africaine", with special reference to the Soudano-Zambesian region. When the flora of this region was being first described, there was little material available, and in some groups further collections have served to link up the earlier described species in a remarkable way, so that to-day certain species prove to have a range of variation much greater than was originally thought possible. $\mathrm{He}$ went on to analyse geographically this range of variation in certain groups, notably in Erythrina, Diplorrhynchus where six described species were shown to be referable to only one with geographical sub-species, and the suffruticose species of Cryptosepalum where there is a quite extraordinary range of variation. He contrasted these genera with others where similar characters have proved to be not only quantitative but qualitative as well and have served to define good species. Prof. Duvigneaud went on to discuss the reasons for the extraordinary range of variation found in some groups, suggesting that it might be due to past climatic changes and introgressive hybridization favoured by a uniform topography. He emphasized the necessity of examining the entirety of material of a species before deciding upon the limits of its variation.

The morphology of the African species of Loranthus was considered by Mlle. S. Balle (Université Libre, Brussels). In the African continent some three hundred species are found, belonging to thirty-two well-characterized groups or sections. The morphological characters of taxonomic importance are mainly derived from the flowers, which show a wide range of structure, the perigone being either gamoor poly-petalous, mostly zygomorphic, but sometimes actinomorphic, with 4-7 segments; the stamen filaments may be erect, reflexed or curled, with or without a tooth, and may show thickening above. 
The morphology of the style also varies. Mlle. Balle compared the characters of groups represented in Africa and those represented in Asia and Oceania. She then analysed the distribution of the different sections in different territories in Africa according to their degree of evolution, finding that the most primitive sections are poorly represented or absent in West Africa but much better represented in East Africa. She finished by posing the problem of whether to maintain Loranthus as a single genus or to split it up into a constellation of smaller genera.

Mr. F. White (Imperial Forestry Institute, Oxford) then discussed "The Distribution of some African Species of Diospyros", the largest and most widespread genus of the Ebenaceae, agreeing with the rejection of $M a b a$ as a distinct genus. Though Diospyros grows in every territory and climatic zone of Africa except the very driest, he presented evidence to indicate that it is essentially a forest genus. $\mathrm{He}$ also directed attention to the concentration of species in the coastal forests of East Africa, where fourteen species occur of which eleven are endemic; nine of the latter have no close affinity with other species of tropical Africa, though two are very closely related to West African species. He gave further examples of vicarious species in East and West Africa.

In a paper on "Pollen Morphology and Taxonomy of Certain African Plants", Prof. G. Frdtman (director of the Palynological Laboratory, Stockholm) showed for the first time some electron micrographs of ultra-thin sections ( $200 \mathrm{~A}$. thick) of pollen grains and spores prepared by a special technique, mainly developed by Dr. Sjöstrand (Stockholm). He then went on to describe various instances among African plants where pollen morphology gives valuable support to taxonomic views already expressed, or makes new suggestions which the taxonomist must consider. The validity of the following families, Dioncophyllacere, Ctenolophonaceae and Barbeyaceae, is thus confirmed. Other suggestions were that Canellaceae may be related to the Magnoliales; that Pentadiplandra has pollen similar to that of Capparidaceae, but not to that of the Olacales; that Jollydora is anomalous in Connaraceae; that Craterogyne is distinct from Trymatococcus; that Choristylis and Itea have similar pollen and may constitute a separate family; that Roussea and Ribes have fairly similar pollen grains; that Kirkia is anomalous in Simaroubaceae; and that an affinity for Thymelaeaceae is to be sought among the crotonoid genera of Euphorbiaceae. Prof. Erdtman finally directed attention to the recently formed International Commission on Palynology and asked that polliniferous or sporiferous material of species of new genera, sub-genera, etc., should be sent to him when they are described, in return for a diagnosis of the pollen grains or spores.

Dr. R. A. Maas Geesteranus (Rijksherbarium, Leyden) discussed two features concerning the lichens of Kenya. Xanthoria parietina, common in the northern hemisphere in nitrogenous or maritime habitats, is also found in North Africa, at the Cape and in a few stations in Kenya at about 2,000 $\mathrm{m}$. altitude, which may be connected with neighbouring soda lakes the dust of which is often widely dispersed by wind. His second topic was the development of lichens in the bamboo zone and the way in which they colonize old bamboo stems, starting at the internodes with crustaceous species, which can survive on atmospheric moisture and retain it, and are then followed by foliaceous and fruticose species. The internodes are ultimately invaded from the nodes.

The nomenclature of the vegetation zones on the mountains of tropical Africa was considered by Prof. A. S. Boughey (University College, Achimota), who pointed out the extraordinary duplication of names given by different authors for the same community, and emphasized the need for some uniform system. He suggested a division into zones rather than belts - since the latter imply too much spatial continuityusing floristic differences as a basis, delimited by differences in altitude. He proposed the following six zones : lowland, $0-800 \mathrm{~m}$.; foothills, 800 $1,500 \mathrm{~m}$.; highland, $1,500-2,100 \mathrm{~m}$. ; montane, 2,100-3,000 m.; temperate, 3,000-4,500 m.; and mountain desert, above $4,500 \mathrm{~m}$. He finished by comparing these proposed zones with those used by Prof. C. G. G. J. van Steenis in Malesia.

Prof. L. Hauman (Brussels) read a paper, "Sur la Nécessité de distinguer une Région afro-alpine pour la Végétation africaine". The high mountains of East Africa are equatorial, and thus the temperatures of their high altitudes are uniformly low. Their high altitudes are isolated climatically and poor floristically, but what plants there are are often remarkable, for example, the giant senecios and lobelias. The genera include many that are temperate but apparently none endemic. Continual cloud causes a great richness of bryophytes. Prof. Hauman proposed to consider the vegetation from the zone of giant lobelias and senecios upwards as constituting the Afro-alpine Zone, lying above the sub-alpine zone of heath-forests.

Dr. O. Hedberg (University of Uppsala) dealt with "Some Taxonomic Problems concerning the Afroalpine Flora", commenting that no allowance for range of variation was made when species were described in the past. By graphical methods he showed continuous variation in such genera as Sebaea and Swertia, resulting in the reduction to synonymy of numerous species previously considered distinct. In these genera, he said, the idea of vicarious species inhabiting different mountains in tropical Africa has been pushed too far on insufficient evidence. He then gave examples of wide variation within one species shown by Senecio keniophytum and Helichrysum citrispinum. He also pointed out that insufficient allowance has been made for hybridization, which certainly occurs among the genera Senecio and Lobelia, and gave a graphical analysis of hybrid populations between two herbaceous species, Senecio mattirolii and $S$. transmarinus, demonstrating that certain previously described species are, in fact, elements of a hybrid swarm between these two. He finally announced that he is engaged on a complete revision of the alpine flora of the East African mountains.

Mr. J. B. Gillett (Royal Botanic Gardens, Kew), who has recently returned from southern Ethiopia, considered the relation between the highland flora of Ethiopia and that of Kenya Colony, with reference especially to recent statements that the Ethiopian highlands form a different phytogeographical region from those of East Africa. Mr. Gillett divided a sample of the flora of the southern margin of the Ethiopian highlands into four groups, as follows: $(B)$ plants confined to Ethiopia south of $10^{\circ} \mathrm{N}$.; $(A B)$ plants also found in the highlands of British East Africa; $(B C)$ plants found in northern Ethiopia ; and $(A B C)$ plants found in all three areas. The totals are : $(B), 10 ;(A B), 41 ;(B C), 12$; and $(A B C), 112$. 
These figures indicate that the flora of the southern Ethiopian highlands is more closely related to that of the British East African highlands than to that of northern Ethiopia, in spite of the formidable obstacle to the spread of highland plants now presented by the low arid country of northern Kenya.

In a paper on "Some Aspects of the Vegetation of Ruwenzori", Mr. R. Ross (British Museum, Natural History) gave some observations made on the recent expedition to Ruwenzori of which he was a member, discussing particularly the zonation of vegetation. He recognizes the following zones: $1,200-2,100 \mathrm{~m}$., Pennisetum savannah. 2,100-2,600 m., montane forest : probably complex, much affected by climatic and biotic factors-for example, elephants. 2,600$3,100 \mathrm{~m}$., bamboo zone: divisible into four topographical types, two characterized by Ericaceae, thus simulating the true ericaceous zone higher up. 3,100-3,300 m., Rapanea-Hagenia forest: a tre日 lobelia and senecio occur. 3,300-3,900 m., ericaceous zone: Philippia longifolia forest dominant, mostly about $10 \mathrm{~m}$. high, sometimes less ; a bog vegetation of tree senecio and lobelia occurs, to be distinguished from similar communities higher up. 3,900-4,800 m., alpine zone: a mosaic of Alchemilla heath, Heli. chrysum scrub and tree senecio forest; these may be intermingled where the soil is continually wet. Above 4,800 m., glaciers.

Mr. Ross particularly noticed a repetition at different altitudes of communities similar in appearance but floristically different.

\section{J. P. M. BRENAN}

\section{GENETICS AND PLANT PATHOLOGY}

$\mathrm{T}$ HE breeding of resistant strains offers a valuable means of reducing the loss of production caused by disease in our domestic plants; but if his work is to be efficient and successful the breeder must enjoy the co-operation of the plant pathologist. A welcome opportunity for a joint discussion of their common problems was provided for pathologist and breeder at the meeting of the British Mycological Society held at Birkbeck College, London, on October 16. The subject was "Genetical Aspects of Plant Disease" and the chair was taken by Dr. C. J. Hickman.

In the introductory paper, Prof. K. Mather sketched in the nature of the host-disease relation from the genetical point of view. Host and pathogen are in permanent conflict : resistance in one puts a selective advantage on virulence in the other, while virulence in its turn puts a premium on new resistance. The situation is seen almost diagrammatically with bacteria and their phages. Exposure to the phage will select out the few resistant mutants from a colony of susceptible bacteria. The resistant colonies grown from these will in their turn select out mutants with new powers of attack from the, to them, otherwise innocuous phage; and so on. In bacterium and phage these changes are attributed to fresh mutation, but in higher plants and fungi a store of variation exists as a permanent feature of populations and species, both in the wild and in domestication. The variation affects properties of resistance and pathogenicity as well as all the other characters, morpho. logical and physiological, of the plant, so that the selection of new mutant forms of the crop or virulent strains of the disease need not wait on the chances of mutation.

The mode of storage of the variability and its availability to selection depend on the system of variation of the species. In erop plants it may exist within varieties where cross-breeding is the rule, or between varieties of inbreeders, or in wild relatives of the domestic species. The breeder may draw on any of these for the raw materials of improved resistance. The systems of variation in fungi are less well understood; but there can be little doubt that variation for pathogenicity is common in the wild. The variation may be stored by genic balance within nuclei and released by sexual recombination, or it may be hidden by balance between nuclei in heterokaryons and released by sorting out in asexual spore production. The reaction of the fungal population in producing new pathogenic strains to the introduction of resistant host varieties must clearly depend on the system of variation. A fuller understanding of these systems in fungi is therefore a prime requisite for an adequate programme of breeding for disease resistance.

Mr. E. W. Buxton then gave an account of his investigations into the variation of Fusarium oxy. sporum, the imperfect fungus which causes the yellows disease of Gladiolus. Variation was observed in respect of both morphological characters and pathogenicity in cultures of the fungus isolated from diseased Gladiolus plants. Although some mutation appears to occur, it is too infrequent to account for the variation to be seen in the cultures, which must therefore have been present in the original isolates from the host plants.

While the older cells of the hyphre generally contain but one nucleus, the tip cells have an average of seven nuclei, and anastomoses are common between adjacent hyphæ. Thus all the requirements for the formation of heterokaryons are present, and heterokaryons can indeed be readily synthesized in experiment. The nuclear ratio of a heterokaryon has been shown to vary characteristically with the carbon content and carbon/nitrogen ratio of the medium on which it is grown, adjustmont to the medium taking place in a matter of a few days. There can be little doubt that heterokaryosis is an important factor in the storage of variation for morphological characters, and that it has complicated the taxonomy of this fungal group. Though there is less experimental evidence about variation in pathogenic properties, such variation undoubtedly occurs in the wild and it appears to be uncorrelated with the morphology of the fungus. Heterokaryosis may well be important also in regard to these pathogenic properties, and a number of questions, such as whether the hyphæ in the soil and those which invade host tissues are heterokaryotic, suggest themselves for further study.

The third paper, by Mr. P. R. Day, also dealt with an imperfect fungus, Cladosporium fulvum, which is a serious pest of the tomato. Three resistance genes are known in the tomato, so that $2^{3}$ physiological races of the fungus can be distinguished by all-or. none tests of infectivity. Of the eight possible races, seven have been recognized in Canada and five of these have been found in Britain. The fungus may be heterokaryotic but inoculation tests have so far proved inconclusive and the controlled synthesis of a heterokaryon has yet to be achieved. Marker mutations have been induced in the fungus by irradiation but, porhaps for technical reasons, no mutation affecting pathogenicity has yet been found, even though loss 